Research Article

\title{
Comparison of efficacy and safety of thiocolchicoside and pregabalin in the treatment of acute non-specific low back pain: an open label randomized prospective study
}

\author{
Jui M. Shah ${ }^{1}$, Kamlesh Patel ${ }^{2}$, Manish R. Shah ${ }^{3 *}$, Devang Rana ${ }^{2}$, Supriya Malhotra ${ }^{2}$
}

\author{
${ }^{1}$ 3rd MBBS Student, Smt. NHL \\ Municipal Medical College, \\ Ahmedabad, India \\ ${ }^{2}$ Department of Pharmacology, \\ Smt. NHL Municipal Medical \\ College, Ahmedabad, India \\ ${ }^{3}$ Department of Orthopaedic, \\ Sheth V.S. Hospital, Ellisbridge, \\ Ahmedabad, India \\ Received: 25 July 2016 \\ Accepted: 13 August 2016 \\ *Correspondence to: \\ Dr. Jui Manish Shah, \\ Email: juimshah@gmail.com \\ Copyright: () the author(s), \\ publisher and licensee Medip \\ Academy. This is an open- \\ access article distributed under \\ the terms of the Creative \\ Commons Attribution Non- \\ Commercial License, which \\ permits unrestricted non- \\ commercial use, distribution, \\ and reproduction in any \\ medium, provided the original \\ work is properly cited.
}

\begin{abstract}
Background: The present study was undertaken to study the efficacy and safety of thiocolchicoside, a centrally acting skeletal muscle relaxant, GABA mimetic drug and pregabalin, an anti-epileptic, GABA mimetic drug in the treatment of acute non-specific low back pain.

Methods: The study was carried out at the orthopaedic outpatient department of our hospital. 80 patients were included during the study period of two months. Out of the 80,40 were given pregabalin $75 \mathrm{mg} 1 \mathrm{hs}$ and the rest were given thiocolchicoside $8 \mathrm{mg}$ bd by the prescribing doctor. Patients, aged between 18 60 years having non-radiating low back pain for less than 7 days were selected. The data was collected in a proforma which included the patient's details and the prescribed drugs. The patients were also given notepads to record adverse effects. On day 1, the pain was measured on visual analogue scale. After a week, follow up was done and decrease in pain was measured on the visual analogue scale.

Results: There was significant difference between pre and post visual analogue scale score in both the groups with a p-value of less than 0.0001 . But the difference between the two groups was not statistically significant (p-value 0.0664). In both the groups, patients did not report any adverse effects. Pregabalin has a slower onset than thiocolchicoside however has better efficacy. In India, where the drug abuse risk is higher, pregabalin is a safer choice as skeletal muscle relaxants (thiocolchicoside) should not be given for more than a week.

Conclusions: Pregabalin has better efficacy in treatment of acute non-specific low back pain as compared to thiocolchicoside.
\end{abstract}

Keywords: Acute non-specific low back pain, Comparative, Efficacy, Pregabalin, Thiocolchicoside.

\section{INTRODUCTION}

Non-specific or common low back pain is defined as pain between the costal margins and the inferior gluteal folds, usually accompanied by painful limitation of movement, often influenced by physical activities and posture, and which may be associated with referred pain in the leg. Diagnosing common low back pain implies that the pain is not related to conditions such as fractures, spondylitis, direct trauma, or neoplastic, infectious, vascular, metabolic, or endocrine-related processes. ${ }^{1,2}$ Thus it is defined as "low back pain not attributed to recognizable, known specific pathology".
Low back pain (LBP), a very common complaint among middle aged population affecting $90 \%$ of all adults at least once in a lifetime and is usually associated with "muscle spasm" that is responsible for persistent pain. It is a major health and socioeconomic problem and is associated with high costs of health care, work absenteeism and disablement. There are various treatment measures in the form of drugs for the treatment of mechanical back pain, such as acetaminophen, nonsteroidal antiinflammatory drugs (NSAIDs), topical analgesics, muscle relaxants, opioids, corticosteroids, antidepressants, and anticonvulsants. ${ }^{8-10}$ Despite availability and use of these analgesic agents, pain relief maybe insufficient and unpredictable. There are two 
drugs widely used for symptomatic relief of acute nonspecific low back pain. One is thiocolchicoside, which is chemically related to colchicine, this muscle relaxant is believed to act as a GABA mimetic and glycinergic drug. Combined with NSAIDs, it is being used for painful muscle spasms, such as torticollis, sprains, backache, etc. Second one is pregabalin, which is a newer congener of gabapentin. It has been particularly used for neuropathic pain. The sedative side effects of this drug are less prominent. ${ }^{3}$ Hence this study was planned with two treatment groups, one receiving pregabalin and the other receiving thiocolchicoside. Their efficacies were compared with respect to pain relief and other symptoms of acute low back pain. Aim of the study was to compare the efficacy of thiocolchicoside and pregabalin in the treatment of acute non-specific low back pain and to study the adverse effects of thiocolchicoside and pregabalin in the treatment of acute non-specific low back pain.

\section{METHODS}

\section{Study design}

It was an open labelled randomized study conducted in the orthopaedic department in a tertiary care teaching hospital. The study was conducted over a period of two months ( $1^{\text {st }}$ May, 2015 to $30^{\text {th }}$ June, 2015). Patients were enrolled on the basis of inclusion and exclusion criteria. They were enrolled after obtaining their written consent. Different parameters were used to assess pain level such as visual analogue scale (VAS) score, sleep disturbances, amount of time the patient can sit, stand and walk without experiencing discomfort. The inclusion and exclusion criteria were as follows.

\section{Inclusion criteria}

- $\quad$ Patients of age range 18-60 years.

- $\quad$ Either of the gender.

- Patients with clinical history of non-specific low back pain of less than or equal to.

- 7 days will be included in the study.

- Nonspecific low back pain with an acute episode of recent onset(less than 48 hours) defined by average pain within the last 24 hours equal or more than 5 on the visual analogue scale (VAS).

- Low back pain of diagnostic category 1(low back pain radiating no farther than the intergluteal fold) or 2 (low back pain radiating no farther than the knee).

- Patients who were willing to take medications as directed, to come for follow ups, to give written consent and comply with the protocol requirements.

\section{Exclusion criteria}

- Pregnancy

- Low back pain due to vertebral collapse or of mechanical origin (suspected by history taking and physical examination) such as neoplasm, infection or inflammatory disorders.

- Low back pain of diagnostic category 3(low back pain radiating beyond the knee with no neurologic signs) or 4(low back pain radiating to a precise and entire leg dermatome with or without neurologic signs)

- History of Inflammatory arthritis of Large Joints, or any structural deformity. History of seizure disorder or any recent history of violent trauma, psychiatric or mental diseases or any widespread neurological symptoms.

- History of malignant tumor.

- Patient who have received other therapy \{NSAIDs (including aspirin), muscle relaxant or opioid analgesics, physiotherapy, physical manipulations, invasive intervention, accupuncture therapy within last 48 hours. \}

- History of Immunosuppression, HIV or use of immunosuppressive drugs.

- Inclusion in another study in past 6 months or previous inclusion in this study.

- History of alcohol, drug or narcotics abuse.

- Constant progressive, non-mechanical pain (no relief with bed rest)

- Thoracic pain.

- Patient systemically unwell or having fever, or unexplained weight loss.

- Clinically significant renal dysfunction/ hepatic dysfunction.

- $\quad$ Patient suffering from diarrhoea.

\section{Study plan}

Patient enrolled based on inclusion criteria and exclusion criteria

Randomization based on Odd-even patient enrollment number.<smiles>C=IC</smiles>

At day 0: Filling up of case record form, informed consent form, visual analogue scale before administration of drug. Patient diary to record adverse effects in their own language.

\section{Group A \\ (odd numbers) \\ Thiocolchicoside \\ Dose-8 mg \\ Duration 1 week \\ Frequency 1 bd}

Group B
(Even numbers)
Pregabalin
$75 \mathrm{mg}$
$1 \mathrm{week}$
$1 \mathrm{hs}$

At day 3 -VAS

At day 7- VAS 
The data was entered into Microsoft Excel 2016®. The analysis was performed by SPSS Version $22 \AA$. The difference between the thiocolchicoside and pregabalin group before and after administration of the respective drugs were compared using unpaired t-test and the VAS score in each group at baseline as well after drug administration was compared using the paired t-test. Pvalue of 0.05 was considered significant.

\section{RESULTS}

\section{Demographic details}

Total number of patients recruited in the study were 80 . No patients discontinued the therapy prematurely. The total mean age was 36.25 years. Mean age group for pregabalin was 38.97 years. Whereas mean age group for thiochochicoside was 33.50 years (Table 1). The ratio of males and females included in the study was 1.105:1.

Table 1: Age distribution.

\begin{tabular}{|lll|}
\hline Age group & Pregabalin & Thiocolchicoside \\
\hline $11-20$ & 2 & 4 \\
\hline $21-30$ & 16 & 16 \\
\hline $31-40$ & 7 & 12 \\
\hline $41-50$ & 2 & 4 \\
\hline $51-60$ & 11 & 3 \\
\hline $61-70$ & 1 & 1 \\
\hline $71-80$ & 1 & 0 \\
\hline
\end{tabular}

Most of the patients included in the study were either housewives $(30 \%)$ or businessmen (16.25). Only one patient had allergy to nimesulide. No patient had a family history of back pain. No patient was suffering from addiction. No patient had radiating pain. On day 0 , maximum number of patients (32) had a visual analogue scale (VAS) score of 6 and 7. After a week, that score had decreased to 4 and 3.

There was a significant difference between pre and post VAS score in both the groups at a p-value of less than 0.0001.But, the difference between the two groups was not statistically significant (p-value 0.0664 ).

In our study, pregabalin shows onset of action from $2^{\text {nd }}$ day and reaches a peak on the 3rd day, whereas in thiocolchicoside, effect starts from $1^{\text {st }}$ day itself and reaches a peak on the $2^{\text {nd }}$ day. The effect of both the drugs decrease gradually after the $3^{\text {rd }}$ day. Thus, thiocolchicoside has faster onset of action as compared to pregabalin (Table 2), (Figure 2).

After one week of treatment with pregabalin, out of five, two patients had improvement in their sleeping patterns. Whereas for thiocolchicoside, out of five, only one patient had improvement (Table 3), (Table 4).
Table 2: Vas comparision.

\begin{tabular}{|c|c|c|c|c|c|c|c|c|c|c|}
\hline & & \multicolumn{9}{|c|}{ visual analogue scale (vas) score } \\
\hline & Time & 0 & 1 & 2 & 3 & 4 & 5 & 6 & 7 & 8 \\
\hline Pregab & Day 0 & 0 & 0 & 0 & 0 & 0 & 5 & 14 & 18 & 3 \\
\hline Pregab & 1 week & 2 & 0 & 8 & 6 & 15 & 7 & 2 & 0 & 0 \\
\hline Thiocol & Day 0 & 0 & 0 & 0 & 0 & 0 & 1 & 21 & 14 & 4 \\
\hline Thiocol & 1 week & 0 & 0 & 2 & 3 & 4 & 5 & 6 & 0 & 0 \\
\hline \multicolumn{11}{|c|}{ Difference in VAS } \\
\hline & 1 & 2 & & 3 & & 4 & & 5 & & \\
\hline Pregab & 2 & 12 & & 1. & & 7 & & 3 & & \\
\hline Thiocol & 0 & 6 & & 18 & & 1 & & 5 & & \\
\hline
\end{tabular}

Table 3: Sleep difference in pregabalin.

\begin{tabular}{|lllll|}
\hline Time & $\begin{array}{l}\text { No } \\
\text { sleep }\end{array}$ & $\begin{array}{l}\text { Mild } \\
\text { disturbance }\end{array}$ & $\begin{array}{l}\text { No } \\
\text { disturbance }\end{array}$ & Total \\
\hline At day 0 & 3 & 2 & 35 & 40 \\
\hline $\begin{array}{l}\text { After } \\
\text { one } \\
\text { week }\end{array}$ & 0 & 3 & 37 & 40 \\
\hline
\end{tabular}

Table 4: Sleep difference in thiocolchicoside.

\begin{tabular}{|lllll|}
\hline Time & $\begin{array}{l}\text { No } \\
\text { sleep }\end{array}$ & $\begin{array}{l}\text { Mild } \\
\text { disturbances }\end{array}$ & $\begin{array}{l}\text { No } \\
\text { disturbances }\end{array}$ & Total \\
\hline At day 0 & 4 & 1 & 35 & 40 \\
\hline $\begin{array}{l}\text { After } \\
\text { one } \\
\text { week }\end{array}$ & 0 & 4 & 36 & 40 \\
\hline
\end{tabular}

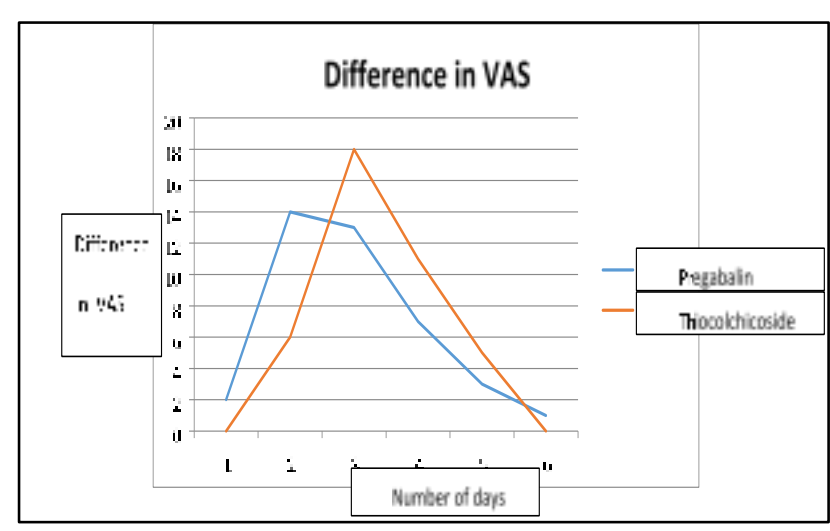

Figure 1: Difference in VAS.

\section{Sitting}

\section{Pregabalin}

When the patients came for the first consultation, 39 patients had no problems in sitting for longer duration, whereas 1 patient could not sit for more than 15-20 minutes due to pain. After one week of treatment, only 1 patient had mild disturbance, whereas the other 39 had no disturbances. 


\section{Thiocolchicoside}

When the patients came for the first consultation, 36 patients had no problems in sitting for longer duration, whereas 1 patient could not sit for more than 20 minutes and 2 patients not more than 30 minutes due to pain. After one week of treatment, only 2 patients had mild disturbance, whereas the other 38 had no disturbances (Table 5).

Table 5: Difference in sitting due to pregabalin.

\begin{tabular}{|lllll|}
\hline Time & $\begin{array}{l}\text { Severe } \\
\text { difficulty }\end{array}$ & $\begin{array}{l}\text { Mild } \\
\text { difficulty }\end{array}$ & $\begin{array}{l}\text { No } \\
\text { difficulty }\end{array}$ & Total \\
\hline On day 0 & 0 & $\begin{array}{l}1 \\
(3-4 \mathrm{hrs})\end{array}$ & 39 & 40 \\
\hline $\begin{array}{l}\text { After one } \\
\text { week }\end{array}$ & 0 & $\begin{array}{l}1 \\
(4-6 \mathrm{hrs})\end{array}$ & 39 & 40 \\
\hline
\end{tabular}

Table 6 Difference in sitting in thiocolchicoside.

\begin{tabular}{|lll|ll|}
\hline Time & $\begin{array}{l}\text { Severe } \\
\text { difficulty }\end{array}$ & $\begin{array}{l}\text { Mild } \\
\text { difficulty }\end{array}$ & $\begin{array}{l}\text { No } \\
\text { difficulty }\end{array}$ & Total \\
\hline On day 0 & 2 & 2 & 36 & 40 \\
\hline $\begin{array}{l}\text { After one } \\
\text { week }\end{array}$ & 0 & 2 & 38 & 40 \\
\hline
\end{tabular}

\section{Standing}

\section{Pregabalin}

When the patients came for the first consultation, 38 patients had no problems in standing for longer duration, whereas 1 patient could not stand for more than 15-30 minutes and one more for maximum 20 minutes due to pain. After one week of treatment, only 2 patients had mild disturbances, whereas the other 38 had no disturbances (Table 7).

Table 7: Difference in standing in pregabalin.

\begin{tabular}{|lllll|}
\hline Time & $\begin{array}{l}\text { Severe } \\
\text { difficulty }\end{array}$ & $\begin{array}{l}\text { Mild } \\
\text { difficulty }\end{array}$ & $\begin{array}{l}\text { No } \\
\text { difficulty }\end{array}$ & Total \\
\hline On day 0 & 1 & 1 & 38 & 40 \\
\hline $\begin{array}{l}\text { After one } \\
\text { week }\end{array}$ & 0 & 2 & 38 & 40 \\
\hline
\end{tabular}

Table 8 Difference in standing in thiocolchicoside.

\begin{tabular}{|lllll|}
\hline Time & $\begin{array}{l}\text { Severe } \\
\text { difficulty }\end{array}$ & $\begin{array}{l}\text { Mild } \\
\text { difficulty }\end{array}$ & $\begin{array}{l}\text { No } \\
\text { difficulty }\end{array}$ & Total \\
\hline On day 0 & 2 & 2 & 36 & 40 \\
\hline $\begin{array}{l}\text { After one } \\
\text { week }\end{array}$ & 0 & 4 & 36 & 40 \\
\hline
\end{tabular}

\section{Thiocolchicoside}

When the patients came for the first consultation, 36 patients had no problems in standing for longer duration, whereas 4 patients could not stand for longer durationdue to pain. After one week of treatment, only 4 patients had mild disturbances, whereas the other 36 had no disturbances (Table 8).

\section{Walking}

Pregabalin

When the patients came for the first consultation, 39 patients had no problems in walking for longer duration, whereas 1 patient could not walk for more than 10 minutes due to pain. After one week of treatment, only 1 patient had mild disturbance, whereas the other 39 had no disturbances (Table 9).

Table 9 Difference in walking due to pregabalin.

\begin{tabular}{|lll|lc|}
\hline Time & $\begin{array}{l}\text { Severe } \\
\text { difficulty }\end{array}$ & $\begin{array}{l}\text { Mild } \\
\text { difficulty }\end{array}$ & $\begin{array}{l}\text { No } \\
\text { difficulty }\end{array}$ & Total \\
\hline On day 0 & 0 & 1 & 39 & 40 \\
\hline $\begin{array}{l}\text { After one } \\
\text { week }\end{array}$ & 0 & 1 & 39 & 40 \\
\hline
\end{tabular}

\section{Thiocolchicoside}

When the patients came for the first consultation, 39 patients had no problems in walking for longer duration, whereas 1 patient could not walk for more than 5-10 minutes due to pain. After one week of treatment, all 40 patients had no disturbances (Table 10).

\section{Table 10: Difference in walking due to} thiocolchicoside.

\begin{tabular}{|lllll|}
\hline Time & $\begin{array}{l}\text { Severe } \\
\text { difficulty }\end{array}$ & $\begin{array}{l}\text { Mild } \\
\text { difficulty }\end{array}$ & $\begin{array}{l}\text { No } \\
\text { difficulty }\end{array}$ & Total \\
\hline On day 0 & 1 & 0 & 39 & 40 \\
\hline $\begin{array}{l}\text { After one } \\
\text { week }\end{array}$ & 0 & 1 & 39 & 40 \\
\hline
\end{tabular}

The patients were given notepads to record the adverse effects. Patients taking pregabalin complained of sedation as an adverse effect. 12 patients out of the total 40 taking pregabalin complained of sedation. 5 patients complained of drowsiness. Patients taking thiocolchicoside did not complain of any adverse effects.

\section{DISCUSSION}

Total numbers of patients enrolled from either sex were 80. Out of 42 males enrolled, 18 and 24 males were assigned to pregabalin and thiocolchicoside group respectively. Whereas, out of 38 females enrolled, 22 and 16 females were assigned to pregabalin and thiocolchicoside group respectively. Mean age of patients was 36.25 years and mean body weight was $65.60 \mathrm{kgs}$. In our study, none of the patients discontinued the therapy prematurely, whereas, in a study done by Freynhagen R et 
al, 3 and 2 patients respectively, discontinued the treatment prematurely. ${ }^{4}$

On evaluation of efficacy of pregabalin and thiocolchicoside-treated group of patients by visual analogue scale (VAS), it was found that, there was statistically significant difference between pre and post VAS score in both the group with the p-value $<0.0001$. But the difference between the two group was not statistically significant ( $\mathrm{p}$-value $=0.0664)$.

In our study, pregabalin shows onset of action from $2^{\text {nd }}$ day and reaches a peak on the $3^{\text {rd }}$ day, whereas in thiocolchicoside, effect starts from $1^{\text {st }}$ day itself and reaches a peak on the $2^{\text {nd }}$ day. The effect of both the drugs decreases gradually after the 3rd day. Thus, thiocolchicoside has faster onset of action as compared to pregabalin.

On the contrary, in the study done by Soonawalla DF et al, there was a decrease in the VAS score, however they did not mention the exact decrease. ${ }^{5}$ Moreover, in the study done by Lahoti $G$ et al, there was significant decrease in the VAS score, which is in accordance to our study. ${ }^{6}$

It is documented that the efficacy of pregabalin is due to enhancement of GABA release. Another theory states that, it modulates a subset of neuronal voltage sensitive calcium channels which contain a2d-1 subunits. It is postulated that decreased entry of calcium into the presynaptic neuron through these channels could reduce glutamate release, lowering neuronal excitability. ${ }^{3}$

On the other hand, action of thiocolchicoside is because of its GABA-mimetic and glycinergic properties. It selectively depresses spinal and supraspinal polysynaptic reflexes involved in the regulation of muscle tone without significantly affecting monosynaptically mediated stretch reflex. Polysynaptic reflexes in the ascending reticular formation are also depressed though to a lesser extent. ${ }^{3}$

On assessment of sleep parameter in pregabalin and thiocolchicoside-treated patients during their first consultation, 35 patients had no sleep disturbances, whereas 5 patients had mild to moderate sleep disturbances due to pain in both the groups. ${ }^{7,8}$ However, after one week of treatment, only 3 patients had mild sleep disturbances, while, remaining 37 had no sleep disturbances in pregabalin - treated group, whereas, only 4 patients had mild sleep disturbances, while remaining 36 had no sleep disturbances in thiocolchicoside - treated group.

In our study, patients taking pregabalin complained of sedation. However in our study, sedation helped the patients alleviate the sleep disturbances. Hence, instead of being a side effect, it actually helped the patients.
In a study done by Freynhagen $\mathrm{R}$ et al, significant and rapid improvements were noted in the sleep interference score $(\mathrm{p}<0.00001){ }^{4}$

In pain during sitting, standing and walking conditions, patients showed remarkable improvement throughout the study. In spite the small sample size, the greatest merit of our study was that it was a comparative study. Pregabalin has been proven effective for chronic neuropathic pain. The fact that it works for low back pain without radiation for patients presenting in an orthopaedic outdoor department possibly shows a correlation between even simple back pain and neurological involvement. ${ }^{9,10}$

This study was a short term study done within a span of 2 months only. There is a lot of scope in the field of pain management. Studies in different parts of the world on a larger scale can be conducted.

\section{CONCLUSION}

There was significant difference between pre and post VAS score in both the group at a $p<0.0001$. But, the difference between the two groups was not statistically significant (p-value 0.0664). In both the groups, patients did not report any adverse effects.

\section{ACKNOWLEDMENTS}

Authors would like to thank Dr. Pankaj R. Patel, Dean, Smt. NHL Municipal Medical College, Dr. Falguni Majmudar, Pharmacology Department, Smt. NHL municipal medical college for their support in work.

\section{Funding: ICMR Short Term Studentship Programme Conflict of interest: None declared}

Ethical approval: The study was approved by the Institutional Ethics Committee

\section{REFERENCES}

1. Deyo RA, Weinstein J. Low back pain. N Engl J Med. 2001;344:363-71.

2. Waddell G. The Back Pain Revolution. Edinburgh. Churchill Livingstone. 1998.

3. KD Tripathi: Essentials of Medical Pharmacology, 7th edition; 358:420.

4. Freynhagen R, Grond S, Schupfer G, Hagebeuker A, Schmelz M, Ziegler D, et al. Efficacy and safety of pregabalin in treatment refractory patients with various neuropathic pain entities in clinical routine. Int J Clin Pract. 2007;61(12):1989-96.

5. Soonawalla DF, Joshi N. Efficacy of thiocolchicoside in Indian patients suffering from low back pain associated with muscle spasm. J Indian Med Assoc. 2008;106(5):331-5.

6. Lahoti G. To evaluate efficacy and safety of fixed dose combination of aceclofenac + paracetamol + thiocolchicoside (acenac-MR) in the treatment of 
acute low back pain. J Indian Med Assoc. 2012;110(1):56-8.

7. Sakai Y, Ito K. Comparison of pregabalin and opioids for chronic low back pain in elderly patients. Eur Spine J. 2015;24(6):1309-17.

8. Plapler PG, Scheinberg MA, Ecclissato CDC, Oliveira MFB, Amazonas RB. Double-blind, randomized, double-dummy clinical trial comparing the efficacy of ketorolac trometamol and naproxen for acute low back pain. Drug Des Devel Ther. 2016;10:1987-93.
9. Chou R, Deyo R, Friedly J, Skelly A, Hashimoto R. Noninvasive treatments for low back pain. Rockville (MD): Agency for Healthcare Research and Quality (US); 2016:16-EHC004-EF.

10. Friedman BW, Andrew A, Davitt M, Holden L, Solorzano C, Esses D. Naproxen with cyclobenzaprine, oxycodone/acetaminophen, or placebo for treating acute low back pain: a randomized clinical trial. J Am Med Asso. 2015;314(15):1572-80.

Cite this article as: Shah JM, Patel K, Shah MR, Rana D, Malhotra S. Comparison of efficacy and safety of thiocolchicoside and pregabalin in the treatment of acute non-specific low back pain: an open label randomized prospective study. Int $\mathbf{J}$ Basic Clin Pharmacol 2016;5:1733-8. 